\title{
Demonstration of the direct impact of ketamine on urothelium using a tissue engineered bladder model
}

\author{
Michel Bureau, MD; Jérôme Pelletier, BSc; Alexandre Rousseau, MSc; Geneviève Bernard, MSc; \\ Stéphane Chabaud, PhD; Stéphane Bolduc, MD, FRCSC
}

Centre LOEX de I'Université Laval, Génie tissulaire et régénération, Centre de recherche FRQS du CHU de Québec, Axe Médecine Régénératrice, Québec, QC

Cite as: Can Urol Assoc J 2015;9(9-10):E613-7. http://dx.doi.org/10.5489/cuaj.2899

Published online September 9, 2015.

\section{Abstract}

Introduction: Ketamine is a common recreational drug. Severe lower urinary tract symptoms associated with its consumption have been reported, but little is known about the involved mechanisms. The effect of ketamine, which is excreted in urine, was evaluated by its application on an in vitro three-dimensional human tissue-engineered bladder model composed of an urothelium and a submucosa.

Methods: Human urothelial cells were cultured with medium containing various concentrations of ketamine and harvested at different times to obtain growth curves. Using this model, specific activity of caspase-3 was measured to assess the level of apoptosis induced by ketamine. Finally, a human tissue-engineered bladder model was used. Urothelial cells were plated on a stromal layer made of dermal fibroblasts and incubated at the air/liquid interface to allow their differentiation. Ketamine was then put on the mature urothelium using paper or agarose vectors for 48 hours.

Results: The presence of ketamine increased cells' doubling times from 1.26 days for control to 1.38 days $(p=0.14)$ and 1.78 days $(p<0.01)$ for the $0.5 \mathrm{mM}$ and $1.5 \mathrm{mM}$ concentrations, respectively. $5 \mathrm{mM}$ and $10 \mathrm{mM}$ of ketamine led to decline in the major cell population. Exposure to $5 \mathrm{mM}$ ketamine induced apoptosis, confirmed by a 2.5 -fold increase in capase- 3 specific activity from control $(p=0.03)$. The structure and cellular cohesion of the urothelium on the three-dimensional model, especially in the intermediate layers, were severely affected in a concentration dependant fashion with both vectors.

Conclusion: The presence of ketamine in the bladder directly damages the urothelium through the induction of apoptosis.

\section{Introduction}

Ketamine is a non-competitive N-methyl-D-aspartate receptor (NMDA) antagonist. Developed in the 1960s, it is main- ly used as an anesthetic agent and in the management of chronic pain. ${ }^{1,2}$ It is associated with side effects like hallucinations, confusion, delusion and "out-of-body" experiences. $^{3}$ These effects, pleasurable to some, combined with its low cost, have led to its consumption as a recreational drug. It is now a commonly abused drug among young adults at rave parties and dance clubs worldwide. ${ }^{4}$

Less than 10 years ago, reports surfaced of an association between irritative lower urinary tract symptoms (LUTS) and consumption of ketamine. ${ }^{5}$ These reports eventually revealed a new clinical entity: ketamine-induced cystitis (KIC). LUTS have also been observed in patients taking prescribed ketamine for chronic pain. ${ }^{2}$

Although it now seems clear that there is an association between ketamine consumption and deleterious effects on the urinary tract, very little is known about the mechanisms involved.

Ketamine is metabolized by cytochrome p450 in the liver. Its 2 principal metabolites (norketamine and di-hydronorketamine) are excreted primarily in urine and to a much lesser extent in the feces. ${ }^{1}$ High performance liquid chromatographic (HPLC) studies have shown that ketamine and norketamine could be detected in the urine up to 6 days after a single $50 \mathrm{mg}$ dose. ${ }^{6}$

The idea that the presence of ketamine and its metabolites in the urine could be responsible for the damages observed in the urinary tract in KIC patients has been previously suggested, ${ }^{5,7}$ although it has never been demonstrated. In the last decade, we have developed an entirely human tissueengineered vesical equivalent (VE) presenting a mature urothelium and a connective tissue layer. ${ }^{8,9}$ This model offers a unique opportunity to test the aforementioned hypothesis. We first worked with a monolayer urothelial cells model for preliminary experiments and further analyzed the effects of ketamine on our three-dimensional (3D) model. 
Bureau et al.

\section{Methods}

\section{Cell isolation and culture}

Cells were obtained from volunteers after informed and written consent in accordance with our local ethics committee's politics. Fibroblasts were isolated from human skin biopsies as previously described ${ }^{10}$ and cultured with Dulbecco-Vogt modification of Eagle's medium (DMEM; Invitrogen, Burlington, ON) with 10\% fetal bovine serum (FBS; Hyclone, Fisher Scientific, Ottawa, ON) and antibiotics (penicillin [100 U/mL, Sigma, Oakville, ON] and gentamicin [25 $\mu \mathrm{g} / \mathrm{mL}$, Schering, Pointe-Claire, QC]).

Human urothelial cells were extracted from a human urothelial tissue as described by Magnan and colleagues. ${ }^{8}$ They were cultured on a feeding layer of irradiated mouse fibroblasts at a 1:5 ratio using DMEM-Ham medium supplemented with $10 \% \mathrm{FBS}, 10 \mu \mathrm{g} / \mathrm{mL}$ epidermal growth factor (EGF, Austral Biologicals, San Ramon, CA), $0.4 \mu \mathrm{g} / \mathrm{mL}$ hydrocortisone (Calbiochem, San Diego, CA), $5 \mu \mathrm{g} / \mathrm{mL}$ insulin (Sigma), $10^{10} \mathrm{M}$ cholera toxin (Sigma), and antibiotics.

\section{Monolayer growth curves}

To assess the impact of ketamine on urothelial cells, we first used a monolayer model. Human urothelial cells were plated in 24-well plates without the irradiated fibroblast feeding layer at $10000 \mathrm{cells} / \mathrm{cm}^{2}$ at day $1(n=3)$. At day 2, we made the time 0-hour count of trypsinated cells using the Coulter Z2 cell counter (Beckman Coulter, Mississauga, $\mathrm{ON})$. The medium was changed daily in the other wells. We used our supplemented DMEM-Ham medium for controls and added ketamine (Ketalar, Pfizer, New York, NY) to it to reach final concentrations of $0.5 \mathrm{mM}, 1.5 \mathrm{mM}, 5 \mathrm{mM}$ and $10 \mathrm{mM}$ for the 4 tested conditions. Counts were performed up to 72 hours and growth curves were plotted. Along with the counts, we also measured the size of the cells with the Coulter Z2.

\section{Caspase-3 activity dosing}

To test the hypothesis that ketamine might induce apoptosis in urothelial cells, we assessed the specific activity of caspase-3 in cell lysates with the ApoAlert Caspase assay kit (Clontech, Palo Alto, CA) according to the manufacturer's instructions. We worked with the same monolayer model described above using the $1.5 \mathrm{mM}, 5 \mathrm{mM}$ and $10 \mathrm{mM}$ ketamine concentrations $(n=3)$. Total protein content in each lysate was determined with the microBCA protein assay reagent kit (Pierce, Rockford, IL). Fluorescence was assessed with a Varioskan fluorometer (Thermo Scientific). Caspase activity correlated with rate of apoptosis and was reported as fluorescence unit (FU)/min/mg of protein.

\section{Construction of vesical equivalents}

Our entirely human tissue-engineered VE were made using the previously described self-assembly method. ${ }^{11}$ Briefly, fibroblasts were cultured in the presence of $50 \mu \mathrm{g} / \mathrm{mL}$ of ascorbic acid for 28 days to form sheets, which were stacked by three and fused for 4 days to serve as stroma. ${ }^{12}$ Urothelial cells were then seeded on this matrix. They were allowed to proliferate for 7 days, after which the VE were incubated at the air/liquid interface for 21 days to promote the differentiation of urothelium. VE were then ready for our experiments. Throughout the whole process, media were changed 3 times a week.

\section{Ketamine on the VE}

To assess the effect of ketamine on human urothelium, we used our human VE. The urothelium was exposed to ketamine using filter paper (Whatman, GE Healtcare Life Science, Baie d'Urfé, QC) and agarose (Sigma, Oakville, $\mathrm{ON}$ ) vectors. For the filter paper vector, ketamine solutions were prepared with phosphate buffered saline (PBS). Papers of $1 \mathrm{~cm}^{2}$ were soaked in the solutions and deposited on the VE. For the agarose vectors, ketamine was mixed with low melting $1 \%$ agarose to reach the desired concentration of ketamine. We deposited $50 \mu \mathrm{L}$ of each of these solutions on a plate, allowed them to cool down and finally placed them onto the VE. The concentrations tested were $0.5 \mathrm{mM}$, $1.5 \mathrm{mM}, 5 \mathrm{mM}$ and $10 \mathrm{mM}$ with a negative control $(\mathrm{n}=3)$. The VE were incubated with the vectors for 48 hours. At the end of the experiment, biopsies of the areas in contact with the vector and their periphery were collected for histological sections.

\section{Histology}

Histological samples were fixed in $1 \mathrm{X}$ Histochoice tissue fixative (Amresco, Solon, $\mathrm{OH}$ ) for 24 hours and embedded in paraffin. Five-micrometer thick sections were stained with Masson's trichrome.

\section{Statistical analysis}

Differences between values were assessed by bilateral Student's t-test. All data were expressed as mean \pm standard deviation (SD), and overall statistical significance was set at $p=0.05$. 


\section{Results}

\section{Effect of ketamine on urothelial cells growth}

The doubling time of urothelial cells for the control was $1.26 \pm 0.05$ days. The presence of ketamine slowed down the growth for the $0.5 \mathrm{mM}$ and the $1.5 \mathrm{mM}$ concentrations, with doubling times of $1.38 \pm 0.09$ days $(p=0.14)$ and $1.78 \pm 0.10$ days $(p=0.004)$, respectively. For the $5-\mathrm{mM}$ and $10-\mathrm{mM}$ concentrations, there was a major decline in cell population eventually leading to zero-cell counts and infinite doubling time - all cells were dead (Fig. 1). These observations were correlated with direct cell observation under microscope (Fig. 2). The remaining cells were also much smaller in the 5-mM and 10-mM concentrations (Table 1) and had the appearance of apoptotic bodies.

\section{Analysis of caspase-3 activity}

The previous observations led us to test the hypothesis that apoptosis may play a role in the observed growth decline. To test this idea, we measured the activity of caspase-3, a protein involved in the execution of apoptosis. After two days of incubation with ketamine, caspase- 3 activity was $3.81 \pm 0.78 \mathrm{FU} / \mathrm{min} / \mathrm{mg}$ of protein, $3.09 \pm 0.53 \mathrm{FU} / \mathrm{min} /$ $\mathrm{mg}$ of protein $(p=0.27), 9.41 \pm 2.16 \mathrm{FU} / \mathrm{min} / \mathrm{mg}$ of protein $(p=0.03)$ and $0.59 \pm 1.03 \mathrm{FU} / \mathrm{min} / \mathrm{mg}$ of protein $(p=0.01)$ for the control, and the $1.5-\mathrm{mM}$, the $5-\mathrm{mM}$ and the $10-\mathrm{mM}$ concentrations, respectively.

\section{Histologic analysis on 3D VE}

Masson's trichrome analysis of our controls for the filter paper and agarose vectors revealed a normal appearing differentiated urothelium and a normal subepithelial connective tissue layer. A deleterious effect of ketamine was seen on the urothelium with both vectors (Fig. 3). The damage is predominantly in the intermediate layer of the urothelium. Moreover, the epithelial integrity was more preserved in the $0.5 \mathrm{mM}$ condition than with higher concentrations. Interestingly, biopsies taken beside the sites where the vectors were applied had a completely normal urothelium (Fig. 4).

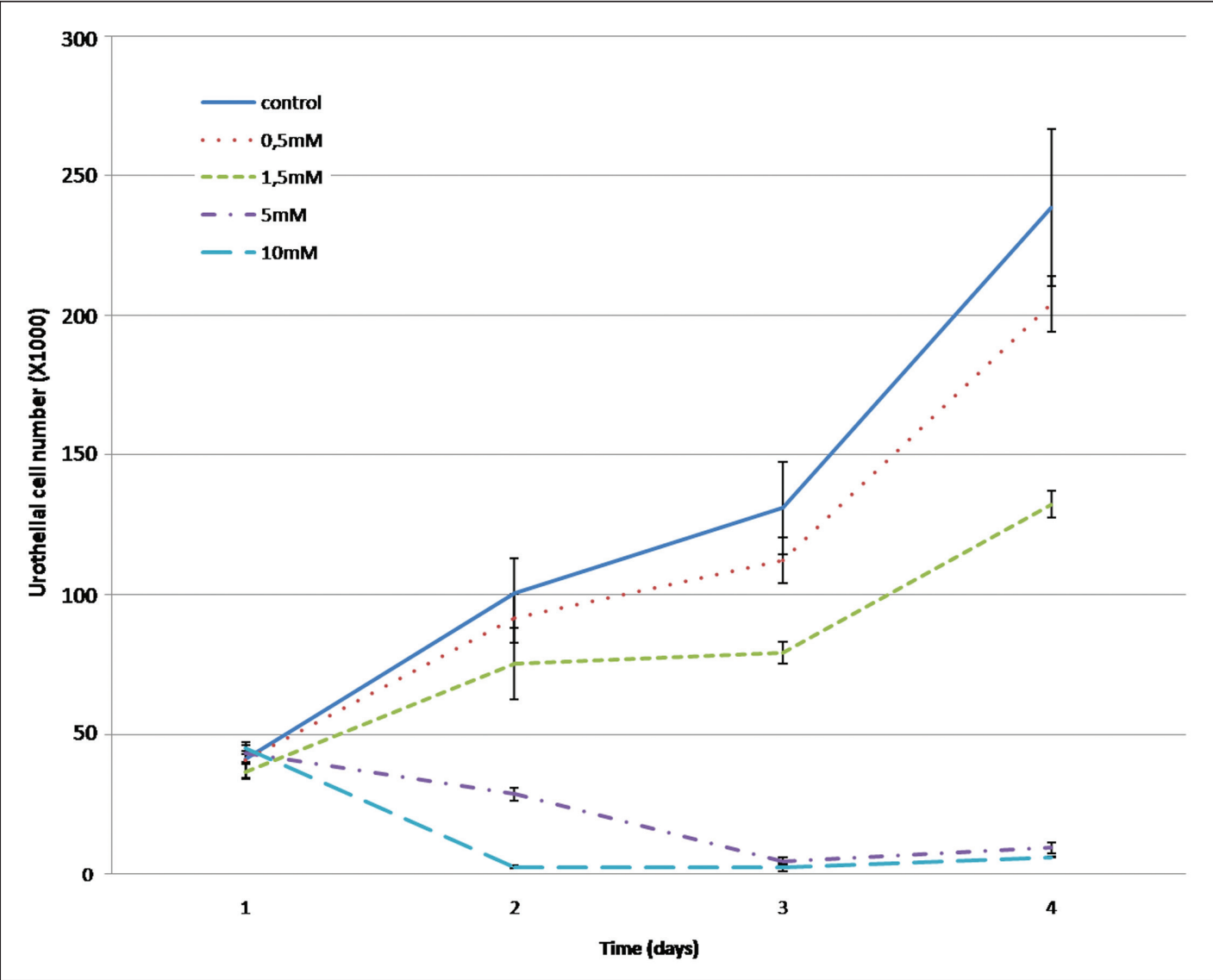

Fig. 1. Three-day growth curves for the 4 ketamine concentrations tested. 


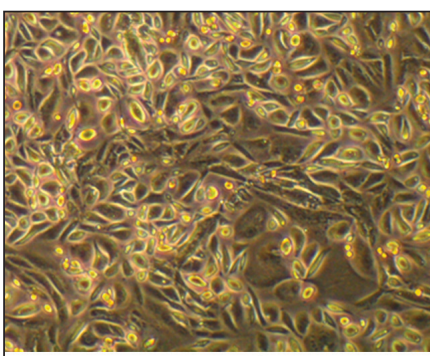

control

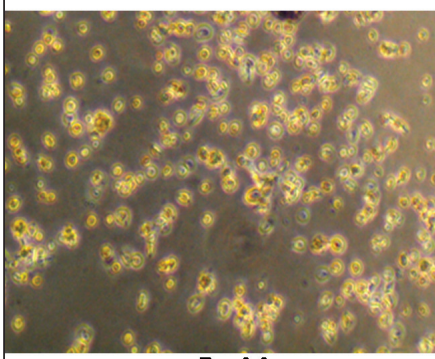

$5 \mathrm{mM}$
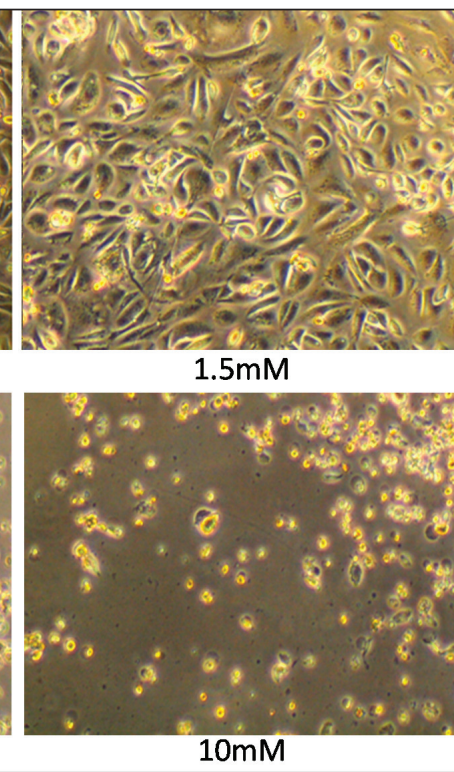

Fig. 2. Urothelial cells after a 72-hour incubation with the various concentrations of ketamine (10xmagnification). The number and size of the cells decreased as the concentration increased. In the last two conditions, the remaining cells have the appearance of apoptotic bodies.

\section{Discussion}

Abacterial cystitis induced by the consumption of ketamine is now a well-documented fact. However the mechanisms underlying this clinical condition are less understood. The hypothesis behind our experiments was that the presence of ketamine in urine, through its renal excretion, could explain the damages sustained by the bladder. This theory has been suggested before, but has never been demonstrated on human tissues, ${ }^{5,7}$ With our work, we confirmed that ketamine has a direct effect on urothelial cells and differentiated urothelium using two-dimensional and 3D models. These deleterious effects are dose dependant and increase with time.

\begin{tabular}{|c|c|c|c|}
\hline \multirow{2}{*}{$\begin{array}{l}\text { Ketamine } \\
\text { concentration }\end{array}$} & \multicolumn{2}{|c|}{ Mean size $(\mu \mathrm{m}) \pm$ standard deviation } & \multirow[t]{2}{*}{$p$ value } \\
\hline & 0 hour & 72 hours & \\
\hline Control & $18.86 \pm 0.14$ & $17.44 \pm 0.29$ & $<0.01$ \\
\hline $0.5 \mathrm{mM}$ & $18.61 \pm 0.10$ & $17.67 \pm 0.03$ & $<0.01$ \\
\hline $1.5 \mathrm{mM}$ & $18.86 \pm 0.12$ & $18.15 \pm 0.17$ & $<0.01$ \\
\hline $5 \mathrm{mM}$ & $18.55 \pm 0.06$ & $13.52 \pm 0.17$ & $<0.0001$ \\
\hline $10 \mathrm{mM}$ & $18.80 \pm 0.07$ & $13.42 \pm 0.22$ & $<0.001$ \\
\hline
\end{tabular}

On the VE exposed to ketamine, we observed that the intermediate portion of the urothelium was mainly affected and the superficial layer was relatively spared. This might be due to greater cohesion between cells and water tightness in the latter layer, which makes it more resistant to ketamine, at least temporarily. In fact, some authors have found in animal models evidence of increased permeability of the urothelium exposed to ketamine and this could explain the damage beyond the superficial layer. ${ }^{13-15}$

As previously mentioned, the presence of apoptotic-like bodies in the monolayer experiments led us to suppose that apoptosis may play a role in the observed growth decline. The presence of apoptosis within the urothelium in patients with $\mathrm{KIC}$ has already been observed. ${ }^{13,16}$ Our data confirmed their findings, but also showed that it is the contact of ketamine with urothelial cells that explains, at least in part, the apoptosis they observed. In our experiment, the caspase-3 activity was maximal for the $5 \mathrm{mM}$ concentration and minimal for the $10 \mathrm{mM}$. Caspase activation is a dynamic process; after a peak of activity, the enzyme turns off. Direct observation under a microscope revealed that the apoptosis process was very advanced after 48 hours in the $10-\mathrm{mM}$ concentration, which likely explains this result.

One of the limitations of our model is the absence of vascular and immune system. As mentioned by some authors, $7,13,17,18$ there could be immunologic and vascular factors involved in KIC that we could not demonstrate with our

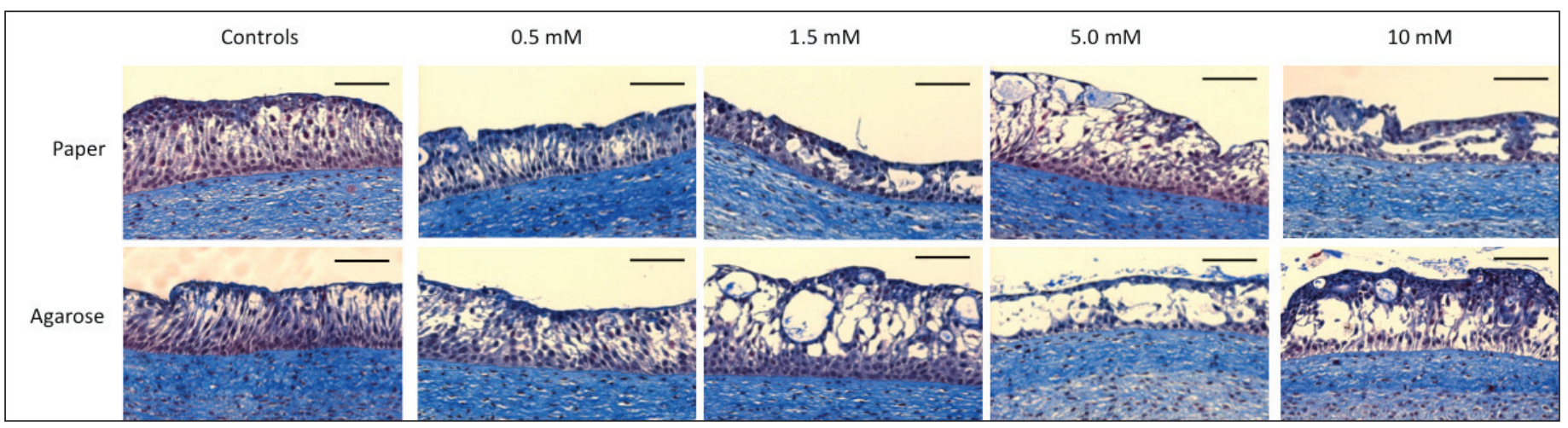

Fig. 3. Masson's trichrome staining of the tissue-engineered vesical equivalents treated with paper and agarose vectors for the $0.5 \mathrm{mM}, 1.5 \mathrm{mM}, 5 \mathrm{mM}$ and 10 $\mathrm{mM}$ concentrations with negative controls. There is increasing damage to the urothelium especially in its intermediate portion as the concentration of ketamine increases. Scale: $100 \mu \mathrm{m}$. 


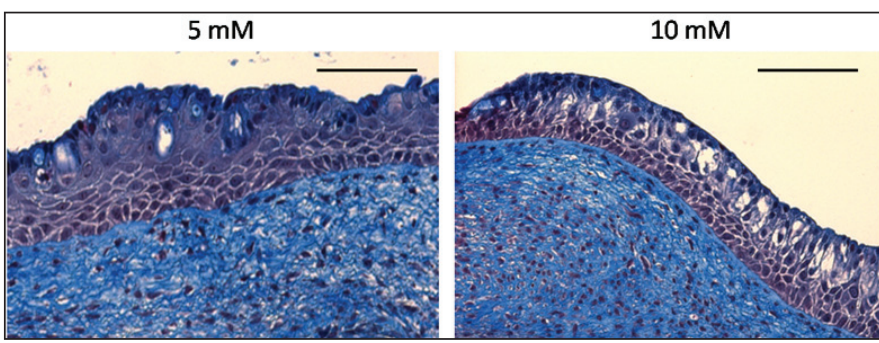

Fig. 3. Masson's trichrome staining of the tissue-engineered vesical equivalents treated with paper and agarose vectors for the $0.5 \mathrm{mM}, 1.5 \mathrm{mM}$, $5 \mathrm{mM}$ and $10 \mathrm{mM}$ concentrations with negative controls. There is increasing damage to the urothelium especially in its intermediate portion as the concentration of ketamine increases. Scale: $100 \mu \mathrm{m}$.

model. Nonetheless, this limitation is also an advantage. It allows us to show the direct attack by ketamine as an independent factor explaining the urothelial damages sustained in KIC.

Recent studies on animal models and histologic samples of KIC patients showed important inflammatory processes and macrophage infiltration. ${ }^{13,15,18}$ It is clear that the direct effect of ketamine is not the only mechanism involved in KIC. However, in the absence of these other phenomenon, we were able to demonstrate that the sole presence of ketamine was enough to induce apoptosis in human urothelial cells in monolayer and on 3D tissue-engineered VE. Moreover, the inflammatory response observed by other authors may likely be the result of the initial direct damages by ketamine.

With our VE, that are among the closest models to human urothelium, we were able to develop a disease-model for $\mathrm{KIC}$. In the future, it will help to further investigate the pathophysiology of KIC. Our disease model can also help develop treatments for $\mathrm{KIC}$ and help prevent its occurrence in patients using ketamine for medical purposes.

\section{Conclusion}

The presence of ketamine in the bladder directly damages the urothelium through the induction of apoptosis and is likely one of the key physiopathologic factors involved in KIC.

Competing interests: The authors declare no competing financial or personal interests.

\section{References}

1. Bergman SA. Ketamine: Review of its pharmacology and its use in pediatric anesthesia. Anesth Prog 1999:46:10-20.

2. Storr TM, Quibell R. Can ketamine prescribed for pain cause damage to the urinary tract? Palliat Med 2009;23:670-2. http://dx.doi.org/10.1177/0269216309106828

3. Wood D, Cottrell A, Baker SC, et al. Recreational ketamine: From pleasure to pain. BJU Int 2011;107:18814. http://dx.doi.org/10.1111/j.1464-410X.2010.10031.x

4. Winstock AR, Mitcheson L, Gillatt DA, et al The prevalence and natural history of urinary symptoms among recreational ketamine users. BJU Int 2012;110:1762-6. http://dx.doi.org/10.1111/j.1464410X.2012.11028.x

5. Shahani R, Streutker C, Dickson B, et al. Ketamine-associated ulcerative cystitis: A new clinical entity. Urology 2007;69:810-2. http://dx.doi.org/10.1016/i.urology.2007.01.038

6. Parkin MC, Turfus SC, Smith NW, et al. Detection of ketamine and its metabolites in urine by ultra high pressure liquid chromatography-tandem mass spectrometry. J Chromatogr B Analyt Technol Biomed Life Sci 2008;876:137-42. http://dx.doi.org/10.1016/i.jchromb.2008.09.036

7. Chu PS, Ma WK, Wong SC, et al. The destruction of the lower urinary tract by ketamine abuse: A new syndrome? BJU Int 2008;102:1616-22. http://dx.doi.org/10.1111/i.1464-410X.2008.07920.x

8. Magnan M, Berthod F, Champigny M.F, et al. In vitro reconstruction of a tissue-engineered endothelialized bladder from a single porcine biopsy. J Pediatr Urol 2006;2:261-70. http://dx.doi.org/10.1016/i. jpurol.2005.11.019

9. Bouhout S, Perron E, Gauvin R, et al. In vitro reconstruction of an autologous, watertight, and resistant vesical equivalent. Tissue Eng Part A 2010;16:1539-48. http://dx.doi.org/10.1089/ten.tea.2009.0473

10. Auger FA, López Valle CA, Guignard R, et al. Skin equivalent produced with human collagen. In Vitro Cell Dev Biol Anim 1995;31:432-9. http://dx.doi.org/10.1007/BF02634255

11. Auger FA, Rémy-Zolghadri $M$, Grenier $G$, et al. A truly new approach for tissue engineering: The LOEX self-assembly technique. Ernst Schering Res Found Workshop 2002;35:73-88. http://dx.doi. org/10.1007/978-3-662-04816-0_6

12. Michel $M$, $L^{\prime}$ Heureux N, Pouliot $R$, et al Characterization of a new tissue engineered human skin equivalent with hair In Vitro. Cell Dev Biol Anim 1999;35:318-26. http://dx.doi.org/10.1007/ s1 1626-999-0081-x

13. Lee CL, Jiang YH, Kuo HC. Increased apoptosis and suburothelial inflammation in patients with ketaminerelated cystitis: A comparison with non-ulcerative interstitial cystitis and controls. BJU Int 2013;112:115662. http://dx.doi.org/10.1111/bju.12256

14. Shen $\mathrm{CH}$, Wang ST, Lee YR, et al. Biological effect of ketamine in urothelial cell lines and global gene expression analysis in the bladders of ketamine injected mice. Mol Med Rep 2015;1 1:887-95.

15. Gu D, Huang J, Yin Y, et al. Long-term ketamine abuse induces cystitis in rats by impairing the bladder epithelial barrier. Mol Biol Rep 2014;41:7313-22. http://dx.doi.org/10.1007/s1 1033-014-3616-5

16. Tan $S$, Chan WM, Wai MS, et al. Ketamine effects on the urogenital system-changes in the urinary bladder and sperm motility. Microsc Res Tech 2011;74:1192-8. http://dx.doi.org/10.1002/jemt.21014

17. Oxley JD, Cottrell AM, Adams $S$, et al. Ketamine cystitis as a mimic of carcinoma in situ. Histopathology 2009:55:705-8. http://dx.doi.org/10.1111/i.1365-2559.2009.03437.x

18. Chuang SM, Liu KM, Li YL, et al. Dual involvements of cyclooxygenase and nitric oxide synthase expressions in ketamine-induced ulcerative cysititis in rat bladder. Neurourol Urodyn 2013;32:1137-43. http:// dx.doi.org/10.1002/nau.22367

Correspondence: Dr. Stéphane Bolduc, Associate Professor, Division of Urology, CHU de Québec (CHUL), 2705, Boul. Laurier, R-1742, Québec, Québec, GIV 4G2; stephane.bolduc@fmed.ulaval.ca

This paper has been peer-reviewed. 